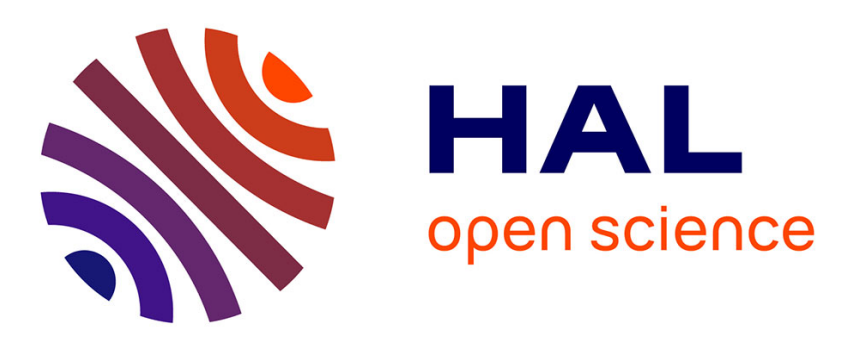

\title{
Adjusting the Tests According to the Perception of Greek Students Who Are Taught Russian Motion Verbs via Distance Learning
}

Oksana Kalita, Georgios Pavlidis

\section{- To cite this version:}

Oksana Kalita, Georgios Pavlidis. Adjusting the Tests According to the Perception of Greek Students Who Are Taught Russian Motion Verbs via Distance Learning. 10th IFIP International Conference on Artificial Intelligence Applications and Innovations (AIAI), Sep 2014, Rhodes, Greece. pp.205-210, 10.1007/978-3-662-44722-2_22 . hal-01391047

\section{HAL Id: hal-01391047 \\ https://hal.inria.fr/hal-01391047}

Submitted on 2 Nov 2016

HAL is a multi-disciplinary open access archive for the deposit and dissemination of scientific research documents, whether they are published or not. The documents may come from teaching and research institutions in France or abroad, or from public or private research centers.
L'archive ouverte pluridisciplinaire HAL, est destinée au dépôt et à la diffusion de documents scientifiques de niveau recherche, publiés ou non, émanant des établissements d'enseignement et de recherche français ou étrangers, des laboratoires publics ou privés.

\section{(ㄷ)(i)}

Distributed under a Creative Commons Attribution| 4.0 International License 


\title{
Adjusting the Tests According to the Perception of Greek Students Who are Taught Russian Motion Verbs via Distance Learning
}

\author{
Oksana Kalita $^{1}$, Georgios Pavlidis ${ }^{2}$ \\ ${ }^{1}$ Peoples' Friendship University, Moscow, Russia \\ kalitaxenia@gmail.com \\ ${ }^{2}$ University of Patras, Patra, Greece \\ pvldseceid.upatras.gr
}

\begin{abstract}
Nowadays, the quantity of digital data is so large that its analysis and evaluation can only be performed through (semi-) automatic methods. In a distance learning context, such problems arise for the teacher who needs to personalize the educational material for specific students. The present study focuses on the personalization of the educational material for Greek students learning the Russian language in a distance learning environment. We discovered that it is important for the Intelligent Tutoring System and more specifically for the Intelligent Agents (IA) to have a set of key-characteristics for a proper representation of the states. By having more features an agent has more accurate results whereas useless features are ignored.
\end{abstract}

Keywords: intelligent tutoring system, trained agents, intelligent test agent, Russian motion verbs, Greek students' preferences

\section{Introduction}

Distance learning platforms and more specifically, the Intelligent Tutoring Systems (ITS) play an increasing and important role in society. Towards an efficient and effective implementation of such systems, the technology of Intelligent Agents (IA) is gradually integrated. Processes are assigned to IA that must be complete under specific limitation [1]. In this way, acting on behalf of the users, they implement an additional type of interaction which is often referred as indirect administration [2].

At the same time, IA can be reeducated and formed in such a way that they will perform an optimal gathering and processing of information. In other words, they will gradually become more efficient by learning the interests, the habits and the preferences of the users and their community [3]. Moreover, they help the members of the educational community to effectively cooperate, to schedule their workload and to take part in common events.

The fact that the IA act without human intervention or intervention from other systems, gives them the desirable autonomy meaning that they have their own control 
practice and can take their own decisions which are presented to the users [4,5]. For this reason, they must be reliable. By taking decisions on behalf of the users, they should guarantee the quality of the services that are provided. Finally, for the efficient communication among the IA, it is essential that they act simultaneously and without interruption so that every process is handled directly [1].

\section{Competence and Confidence}

The purpose of IA is to help the educational community; however this presupposes the resolving of two basic problems. The first one is the competence, i.e. how an IA receives the desired information (knowledge) so as to decide when and how it can help the educational community. Under this scope, the efficiency and the effectiveness will depend on the number of key characteristics as well as on the quality of the information that are accessible from the IA. The second problem concerns confidence, i.e. how the educational community can feel secure when assign tasks to an IA.

An implementation, which is in accordance with the necessary requirements and provides solutions to the above-mentioned problems, is the trained IA, presented by Pattie Maes [6]. One trained IA can develop its competence through four different ways. First, it is trained by monitoring the activities of the user; it records the user's actions and seeks possible repetitions of behavioral patterns which can be automated. Secondly, it is adjusted based on direct or indirect user feedback. Indirect feedback is received when the user ignores the suggestion made by the IA or when negative feedback is given to an automatic IA action. Third, it is trained through explicit examples by the user, who is the one to show what action should be taken at various hypothetical situations. Fourth, it seeks advice coming from others either more experienced or supplementary IA, which support users in similar processes (situations).

This approach boosts confidence by allowing the IA to provide explanations both for the reasoning and for the behavior in a familiar to the user form. For example, it should explain to the students that, we propose you to proceed to this action:

- due to the fact that there is similarity among past preferences for something

- or there is similarity among past actions

- or it was applied by another student with similar preferences.

\section{$3 \quad$ Filtering the information}

Filtering the information that enters and circulates in a ITS was and still remains an open issue theoretically and practically. Its goal is to introduce to users only the information that is relevant to them. Generally, the existing Information Filtering Systems represent a type of an information retrieval system designed for the management of large volume unstructured or semi structured data [7].

There are three basic methods of information filtering: simple, based on the content and collaborative [8,9]. Simple Filtering is based on the categorization of the users in 
groups according to their personal features and their profiles. Thus, an IA will be in the position to send the appropriate information to the members of each category.

In Content-Based Filtering, the content of the existing information is analyzed and a representation of the interests (views) of the educational community members is formed. For this purpose, the teacher has to establish a set of key characteristics for every learning item and then the student has to assign the appropriate values to each characteristic. Content-based filtering uses the Euclidean distance in order to analyze the evaluations of key-characteristics and thus to establish the closer value that could be proposed to the "new" user.

In Collaborative Filtering, the viewpoints of the users about the educational objects are collected, either directly or indirectly, in order to develop clusters of likeminded persons. This system, in contrast with the content-based filtering, proposes information that has been evaluated by students of similar abilities and preferences with the user that receives the new educational material. In this case, the Euclidean distance is also used for the analysis of the values and the designation of information that will be proposed to the user.

\section{$4 \quad$ Intelligent Tutoring Systems}

The Intelligent Tutoring Systems (ITS) represent applications with major knowledge on a specific subject and aim to transfer this knowledge to the students through an interactive individualized process. They are trying to simulate the educational process so that a virtual teacher will guide the student to the learning process. The purpose of each ITS is to effectively convey its incorporated knowledge.

The main problem of ITS lies on their adaptation to the students' needs. In addition, students continuously interact with the system. The adaptation of the user is provided through pedagogical strategies which determine the sequence, the type of given assistance during the teaching and learning procedure, the time frame and the way of presenting the teaching material (problems, definitions, examples etc).

Generally, the architecture of an ITS consists of four basic components: the Student Model, the Field Model, the Pedagogical Unit and the Educational Unit [10]. Moreover, its function is supported by the following intelligent agents: the Preference agent, the Accounting agent, the Activity agent and the Test agent [11]. These IA must cooperate, help and complement each other in a dynamic way.

\section{$5 \quad$ Application Example of a Test Agent}

By extending the functionality of an ITS, we will analyze a way of calculating the suggestions produced by the Test agent, on the basis of the preferences of Greek students who learn Russian motion verbs with prefixes. These verbs cannot be understood by the students since the application of a prefix entails multiple meanings and multiple ways of use. In addition, the same prefixes have similar meanings indicating either proximity or withdrawal at different degree of achievement. There are no 
equivalent verbs in Greek language, which makes the situation more complex and enforces the development of many exercises on behalf of the teachers.

Having successfully finished with the exercises in the test phase, our research indicates confusion among students when all prefixes are used in combination with all pairs of motion verbs. More specifically, some prefixes in Greek language do not exist or have a similar meaning. The testbed of 10 classes of 10 students per class faced a particular difficultly as far as the following three groups of prefixes are concerned: (i) |При-| До-| Под-|, (ii) |Пере-| Про-|, and (iii) |Вы-| У-| (Table 1).

Table 1. Prefixes with similar meaning and usage

\begin{tabular}{|c|c|c|}
\hline \multicolumn{2}{|c|}{ Directional prefixes } & Meaning in Greek (English) \\
\hline \multirow{4}{*}{$\begin{array}{l}\text { with oppo- } \\
\text { sites }\end{array}$} & При- & 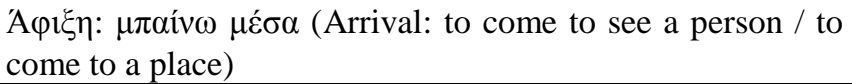 \\
\hline & y- & 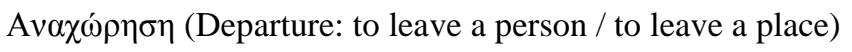 \\
\hline & Вы- & 'E $\xi o \delta o \varsigma$ (Exit: to go out of a place) \\
\hline & Под- & 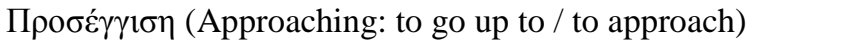 \\
\hline \multirow{3}{*}{$\begin{array}{l}\text { without } \\
\text { opposites }\end{array}$} & Про- & 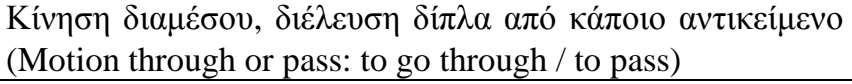 \\
\hline & До- & 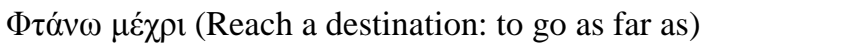 \\
\hline & Пере- & 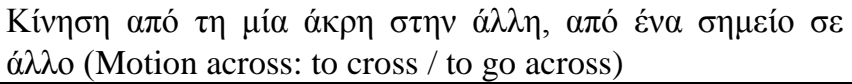 \\
\hline
\end{tabular}

IA suggests some tests to the students from the same category according to collaborative filtering technique the tests are evaluated later. Then, these grades are compared with those of other users, their similarity is estimated and the current user is provided with highly-evaluated activities by users of the same preferences as him/her.

As mentioned above, collaborative filtering technique makes use of the Euclidean distance in order to calculate the degree of evaluation similarity among users. It is assumed that each student can evaluate the activities with the use of a scale ranging from 1 (he/she does not like the activity at all) to 5 (he/she likes it very much), while 3 denotes a neutral opinion.

Let's assume the students A, B and C have evaluated three tests each as Table 2 shows. 
Table 2. Ratings of the tests by the students plus a possible execution route.

\begin{tabular}{|c|c|c|c|c|c|}
\hline & & & Evaluations & & Possible route \\
\hline \multicolumn{2}{|l|}{ Test } & Student A & Student B & Student C & of execution \\
\hline \multirow{3}{*}{$\begin{array}{c}\text { Group } 1 . \\
\mid \text { При-|До-| } \\
\text { |Под-| }\end{array}$} & 1 & $5 \lesssim$ & $2 \lesssim$ & $4 \lesssim$ & $1 \longrightarrow$ \\
\hline & $\ldots$ & $\ldots$ & $\ldots$ & $\ldots$ & \\
\hline & $\mathrm{n}$ & $\ldots$ & $\ldots$ & $\ldots$ & 1.6 \\
\hline \multirow{3}{*}{$\begin{array}{c}\text { Group } 2 . \\
\mid \text { Пере-| } \\
\mid \text { Про-| }\end{array}$} & 1 & $3 \pi$ & - & 5 次 & \\
\hline & $\ldots$ & $\ldots$ & $\ldots$ & $\ldots$ & $\square^{2.3}$ \\
\hline & $\mathrm{m}$ & $\ldots$ & $\ldots$ & $\ldots$ & $2.4 \square$ \\
\hline \multirow{3}{*}{$\begin{array}{l}\text { Group } 3 . \\
\mid \text { Вы-| У-| }\end{array}$} & 1 & - & 4 次 & $1 \lesssim$ & $3.1 \mathrm{~L}$ \\
\hline & $\cdots$ & $\cdots$ & $\cdots$ & $\cdots$ & 3.7 \\
\hline & $\mathrm{p}$ & $\ldots$ & $\ldots$ & $\ldots$ & $\downarrow$ \\
\hline
\end{tabular}

We assume that the current user is $\mathrm{C}$. At first, the Test agent will calculate the Euclidean distance of $\mathrm{C}$ from the other students. For example, the distance between $\mathrm{C}$ and $\mathrm{B}$ for $i$ activities is calculated as follows:

$$
d(X, Y)=\sqrt{\sum_{i=1}^{2}\left(x_{i}-y_{i}\right)^{2}}=\sqrt{\left(x_{1}-y_{1}\right)^{2}+\left(x_{2}-y_{2}\right)^{2}}=\sqrt{5} \approx 2,24
$$

It is noted that only common ratings, in our case that are those of tests 1 and 2, are taken into account. The corresponded Euclidean distance of student $\mathrm{C}$ from student $\mathrm{A}$ is 3,61. It is observed that the student who has the nearest distance from $\mathrm{C}$ is A. Finally, the Test agent will suggest to student $\mathrm{C}$ the most highly-rated activities of student A which haven't been already executed and rated by him/her. In a similar way we implement the proposals from the Activity agent.

\section{Conclusions}

Traditionally, when a teacher and his/her team, prepares the educational material and determines the outlines of the teaching process, he does not take into account the personality and the special characteristics of the students in the audience. The teacher assumes that the audience is a team which is logical because he/she has never a permanent, face to face, contact with all the students. However, this is not the case when the educational process takes place in a virtual, digital world. In such a world, personal contact is restricted or non-existent; nevertheless there is an increasing amount of old and new, primary or secondary external information regarding each of the students. 
The ITS analyze and collect all necessary data from the interaction of students with the system, thus the rate of presenting the contents of the educational material, the learning ability are adjusted to the preferences and the learning styles of each student. They offer invaluable assistance to the teachers, because the student is in a controlled but at the same time in a friendly environment. Moreover, individual proposals allow the avoidance of the student's information overload and improve the interaction with the system.

Our research will be continued with the study of more complex situations of interconnection. Specifically, our goal is the smooth and effective transition from the exercises to the tests, through the collaboration between the Test and the Exercise agent.

\section{$7 \quad$ Bibliography}

1. Jennings, N. R., Wooldridge, M. J.,: Agent Technology, Springer, Berlin (1998)

2. Kay, A.: User Interface: A Personal View, In: The Art of Human-Computer Interface Design, pp. 121-131 (1989)

3. Bentley, T. J.: Managing information: Avoiding Overload, CIMA, London (1998)

4. Leng, J., Lim, C. P., Li, J., Li, D., Jain, L.: A Role-Based Cognitive Architecture for MultiAgent Teaming, In: Håkansson, A. et al. (Eds.), Agent and Multi-Agent Technology for Internet and Enterprise Systems, Berlin, Springer, pp. 226-252 (2010)

5. Franklin, S., Graesser, A.: Is it an Agent, or Just a Program? A Taxonomy for Autonomous, in Jennings, N.R., Wooldridge, M.J., Müller, J.P. (eds.) ECAIWS, vol. 1193, Springer, Heidelberg, pp. 21-35 (1996)

6. Maes, P.: Agents that Reduce Work and Information Overload, In: Communications of the ACM, vol. 34, no. 7, pp. 30-40 (1994)

7. Hanani, U., Shapira, B., Shoval, P.: Information Filtering: Overview of Issues, Research and Systems, In: User Modeling and User-Adapted Interaction, pp. 203-259 (2001)

8. Palme, J.,: Information Filtering, Stockholm (1998)

9. Juszczyszyn, K., Kazienko, P., Musiał, K.: Personalized Ontology-Based Recommender Systems for Multimedia Objects, In: Håkansson, A. et al. (Eds.), Agent and Multi-Agent Technology for Internet and Enterprise Systems, Berlin, Springer, pp. 271-288 (2010)

10. Gascueña, G. M., Fernández-Caballero, A.: An Agent-based Intelligent Tutoring System for Enhancing E-Learning/E-Teaching, In: International Journal of Instructional Technology and Distance Learning, vol. 2, no. 11, pp. 11-24 (2005)

11. Håkansson, A., Hartung R., Nguyen, N. T.: Agent and Multi-Agent Technology for Internet and Enterprise Systems, Springer, Berlin (2010) 